\title{
Qualidade do Emprego nas Culturas de Café, Cana-de-açúcar e Milho: estudo comparativo 2000/2010 entre mesorregiões de Minas Gerais ${ }^{1}$
}

\author{
Maria Raquel Caixeta Gandolfi², Clesio Marcelino Jesus ${ }^{3}$ e \\ Peterson Elizandro Gandolfi ${ }^{4}$
}

Resumo: Este artigo investiga a evolução e a qualidade do emprego rural dos residentes nos setores urbano e rural de Minas Gerais. O recorte analisado compreende as mesorregiões separadas pelo grau de modernização nas culturas de café, cana-de-açúcar e milho, envolvendo os diferentes tipos de empregados agrícolas. Foram investigadas as mesorregiões do Triângulo Mineiro e Alto Paranaíba, Noroeste de Minas, Jequitinhonha, Vale do Mucuri e Rio Doce e Zona da Mata. Para tanto, foram utilizados dados do Censo Demográfico de 2000 e 2010, do Censo Agropecuário de 2006 e da Pesquisa Agrícola Municipal (PAM) para análises em geral e construção do Índice de Qualidade do Emprego (IQE), que tomou como referência de construção a metodologia desenvolvida por Kageyama e Rehder (1993) e Balsadi (2000). Os resultados demonstraram queda no volume total do emprego rural e que as mesorregiões mais modernizadas tendem a possuir maior qualidade do emprego, assim como a presença maior de empregados qualificados, em contraste com as mesorregióes menos modernizadas, em que a significativa maioria dos empregados é constituída por não qualificados. Nesse aspecto, a modernização pode estar acentuando as desigualdades ao ser mais aplicada nas regiões mais desenvolvidas.

Palavras-chaves: emprego agrícola, modernização agrícola, Índice de Qualidade do Emprego (IQE).

Abstract: This paper investigates the evolution and quality of rural employment of residents in Minas Gerais urban and rural sector. The focus was the megaregions of Minas Gerais, distinguished by their degree of modernization, in coffee, sugarcane and corn crops, involving different types of agricultural employees. For that purpose, data from the Demographic Census of 2000's and 2010's, the 2006 Census of Agriculture and the Municipal Agricultural Survey (PAM) were used for general analysis and construction of the Employment Quality Index (IQE), which took as

1. Data de submissão: 26 de junho de 2017. Data de aceite: 26 de fevereiro de 2018.

2. Universidade Federal de Uberlândia, Uberlândia-MG, Brasil. E-mail: raquelcgandolfi@ufu.br

3. Universidade Federal de Uberlândia, Uberlândia-MG, Brasil. E-mail: clesiomj@gmail.com

4. Universidade Federal de Uberlândia, Uberlândia-MG, Brasil. E-mail: petersongandolfi@gmail.com 
construction reference the methodology developed by Kageyama and Rehder (1993) and Balsadi (2000). We analyzed Triângulo Mineiro and Alto Paranaíba, Noroeste de Minas, Jequitinhonha, Vale do Mucuri and Rio Doce e Zona da Mata megaregions. The results showed a decrease in the total rural employment and that more modernized mesoregions tend to have a higher quality of employment, as well as the greater presence of qualified employees, in contrast to the less modernized mesoregions, where most of employees are not qualified staff. In this context, modernization may be reinforcing inequalities by being more applied in favor of more modernized regions.

Key-words: agricultural employment, employment, agricultural modernization, new ruralism, Job Quality Index (IQE).

Classificação JEL: J43, J81, Q1, R1.

DOI: http://dx.doi.org/10.1590/1234-56781806-94790570104

\section{Introdução}

A intensificação da agricultura capitalista moderna, entre outras transformações, provocou profundas modificações nas relações sociais de produção, com fortes impactos sobre o emprego rural. O intenso dinamismo da produção agrícola também modificou o padrão do mercado de trabalho agrícola no Brasil (MAIA; SAKAMOTO, 2014). À medida que novas tecnologias foram introduzidas nas culturas (café, cana-de-açúcar e milho), principalmente a mecanização na fase da colheita, o resultado foi a promoção de um saldo negativo para o emprego rural.

Conforme apontam Ortega e Jesus (2012), ao analisarem o processo de modernização do café no Cerrado Mineiro, reduziu-se a demanda por mão de obra temporária e desqualificada, trabalhadores braçais, em sua maioria, e aumentou-se a demanda por trabalhadores qualificados e especializados, como tratoristas, mecânicos, operadores de máquinas etc. Dessa forma, trabalhadores não qualificados, antes inseridos na produção agrícola, principalmente na fase da colheita, passaram a atuar em outras atividades que exigem pouca qualificação, como a construção civil, ou passaram a formar um contingente de mão de obra rural desempregada ou subempregada e de baixa qualificação.

Até o final dos anos 1970, os impactos negativos do processo de modernização da agricultura brasileira eram atenuados pela expansão do emprego industrial urbano, decorrendo esses impactos das políticas industrializantes conduzidas pelo Estado. Entretanto, a par- tir dos anos 1980, a capacidade do setor industrial de atenuar a queda contínua do emprego na agricultura começou a se enfraquecer e a perder seu dinamismo.

Essa realidade é percebida nos últimos anos, no Brasil, e por regiões, nas quais tem ocorrido queda do emprego agrícola no meio rural, resultado, sobretudo, da modernização de natureza conservadora e desigual, que formou no âmbito rural agrícola um excedente de mão de obra que não conseguiu ser absorvido, principalmente, o trabalhador não qualificado. Além disso, no estado de Minas Gerais, assim como no Brasil, essa incapacidade foi agravada pelas políticas de favorecimento à grande propriedade e à mecanização em uma economia subdesenvolvida (GRAZIANO DA SILVA, 1999).

No estado mineiro, as mesorregiões com maior dificuldade para formação de capital, denominadas menos modernizadas, foram as que mais sofreram as consequências da modernização. Logo, a desigualdade entre as mesorregiões e a importância do estado no cenário da produção agrícola nacional justificam os estudos cujo período de análise compreende os anos de 2000 e 2010, referentes à realização dos censos demográficos, base de dados utilizada para a construção do Índice de Qualidade do Emprego (IQE).

Em síntese, o objetivo deste artigo é o de investigar como evoluiu a qualidade do emprego (medido pelo IQE) rural agrícola para as culturas de café, cana-de-açúcar e milho, na década de 2000, comparando-se as mesorregiões consideradas mais modernizadas (Triângulo Mineiro e Alto Paranaíba, e Noroeste de Minas) com as mesorregiões consideradas menos 
modernizadas (Jequitinhonha, Vale do Mucuri, Vale do Rio Doce e Zona da Mata) no estado de Minas Gerais. Especificamente, pretende-se calcular e analisar o Índice de Qualidade do Emprego (IQE) para as mesorregiões mais e menos modernizadas diferenciando-as por empregos qualificados e não qualificados, com domicílio urbano ou rural.

Para tanto, o artigo foi elaborado em três seções, além dessa introdução e das considerações finais. $\mathrm{Na}$ primeira seção, foi realizada breve caracterização do processo de modernização agrícola e definição das culturas e mesorregiões a serem estudadas no estado de Minas Gerais. Na segunda, foi explanada a metodologia do trabalho e, na terceira, foram apresentados os resultados e as análises do emprego rural.

\section{Breve caracterização do processo de modernização agrícola em Minas Gerais e a definição das culturas e mesorregiões estudadas}

Segundo informações da Fundação João Pinheiro (2000), a modernização agrícola em Minas Gerais tem ocorrido mais fortemente desde a década de 1990, principalmente, no Triângulo Mineiro e Alto Paranaíba (TMAP), onde o uso intensivo de máquinas, de adubos e de corretivos possibilitou ganhos produtivos e de capital. Essa modernização caracterizou-se como parcial por não contemplar todas as mesorregiões do estado e, com isso, promoveu disparidades regionais, pelas quais grande parte das propriedades mineiras deixou de ser contempladas com os seus benefícios, ficando à margem do processo.

Ferreira Júnior et al. (2004), em seu estudo sobre a modernização agropecuária em Minas Gerais, avaliaram as mudanças na estrutura produtiva no estado, demonstrando uma íntima relação com os avanços tecnológicos e identificando desde as mais rudimentares técnicas aos mais elevados níveis de tecnologia nas diferentes microrregiões do estado. Seguindo a mesma linha, Bastos e Gomes (2011) ressaltam a disparidade no desenvolvimento das regiões, em virtude da extensão territorial do estado, além de outros fatores, comparando o intenso uso de capital no TMAP com o regresso tecnológico no Vale dos rios Jequitinhonha e Mucuri.

Ferreira Júnior, Baptista e Lima (2004) destacam que as transformações ocorridas no setor agropecuá- rio brasileiro têm evidenciado a forte relação existente entre modernização agropecuária e nível tecnológico. Além disso, os trabalhos de Figueiredo (1996) e Kageyama e Leone (2002) complementam essa afirmação, chamando a atenção para o fato de que o processo de modernização agrícola brasileiro está associado à uma produção apoiada no uso combinado e intensivo de insumos modernos, tais como máquinas e tratores, fertilizantes químicos e corretivos e controle químico de pragas e doenças, o que resulta em alta produtividade do trabalho e da terra. Essas transformações foram demonstradas por Ortega e Jesus (2012), quando analisam a produção de café no TMAP.

Diante de tais transformações, verifica-se que as políticas que visam a modernização da agricultura e a elevação da sua produtividade devem ser direcionadas às regiões e aos municípios mais atrasados tecnologicamente, de modo a aperfeiçoar esses recursos, dada a escassez de recursos governamentais. Dessa forma, qualquer política de modernização da agricultura deve considerar as variáveis que definem o padrão tecnológico empregado nas atividades dos diferentes municípios que compõem uma região, bem como detectar suas semelhanças e diferenças, a fim de que sejam adotadas políticas de apoio específicas e coerentes para grupos distintos de municípios homogêneos em diferentes regiões.

Entretanto, conforme analisam Kageyama e Silveira (1997), “[...] o processo de convergência de rendas observado entre países ou entre regiões dificilmente estaria ocorrendo entre os estados brasileiros" (p. 22). Essa situação condiz com Minas Gerais, onde há alta heterogeneidade das mesorregiões, encontrando-se desde aquelas mais modernizadas e dinâmicas, como Triângulo Mineiro e Alto Paranaíba e Noroeste de Minas, e que foram favorecidas por políticas públicas do governo na região dos cerrados, bem como as menos dinâmicas, com predomínio ainda de formas artesanais de produção e agricultura familiar, como o Vale do Mucuri e Jequitinhonha.

Para Ribeiro, Ayres e Assis (2003),

[...] trabalhadores rurais foram desempregados em Minas Gerais, pela modificação no sistema de produção, que passaram a incorporar a mecanização e a técnica agrícola intensiva, tornando desnecessária a presença de muitos empregados (p. 127). 
Tabela 1. Número de empregados (com e sem carteira assinada) nas culturas agrícolas, em todas as mesorregiões do estado de Minas Gerais

\begin{tabular}{lccccc}
\hline \multirow{2}{*}{ Código da cultura } & Descrição das culturas & \multicolumn{2}{c}{ Censo 2000 } & \multicolumn{2}{c}{ Censo 2010 } \\
\cline { 2 - 6 } & Café & $\begin{array}{c}\text { Número de } \\
\text { empregados }\end{array}$ & Var (\%) & $\begin{array}{c}\text { Número de } \\
\text { empregados }\end{array}$ & Var (\%) \\
\hline 1113 & Milho & 343.846 & $70,8 \%$ & 188.729 & $65,3 \%$ \\
1102 & Cana-de-açúcar & 34.297 & $7,1 \%$ & 27.144 & $9,4 \%$ \\
1105 & 12.635 & $2,6 \%$ & 13.136 & $4,5 \%$ \\
\hline Subtotal - Participação do café, cana-de-açúcar e milho & 390.779 & $80,4 \%$ & 220.003 & $76,1 \%$ \\
\hline Outros - Demais produtos de lavoura temporária e permanente & 95.120. & $19,6 \%$ & 63.031 & $23,9 \%$ \\
\hline Total & 485.899 & $100 \%$ & 289.034 & $100 \%$ \\
\hline
\end{tabular}

Fonte: Elaboração própria com base nos microdados do IBGE, Censo Demográfico (2000) e Censo Demográfico (2010).

Os autores distinguem o trabalho rural nas "muitas Minas", diferenciando as regiões marcadas pela presença da unidade rural familiar, como Zona da Mata, Vale do Mucuri e Jequitinhonha, que se caracterizam por menor produção e maior ocupação (por produto), daquelas regiões mais patronais e intensivas, como o TMAP e Noroeste de Minas (maior produção e menor ocupação por produto), caracterizadas por maior produtividade e rendas mais elevadas para o pessoal ocupado na agropecuária.

Assim sendo, considerando o impacto sobre o trabalhador rural em Minas Gerais, o presente trabalho foi direcionado para as culturas que mais empregam. De acordo com os dados da Tabela 1, entre as principais culturas em relação ao número de empregados na agricultura de Minas Gerais, o café ocupa o primeiro lugar $(70,8 \%$, em 2000 , e $65,3 \%$, em 2010$)$, seguido do milho $(7,1 \%$, em 2000 , e $9,4 \%$, em 2010$)$ e cana-de-açúcar (2,6\%, em 2000, e 4,5\%, em 2010). Nessa lógica, a análise foi aplicada a essas três culturas que, juntas, representam $80,4 \%$ da representação dos empregados alocados em 2000 e 76,1\%, em 2010.

Após a definição das principais culturas agrícolas, buscou-se identificar entre as 12 mesorregiões mineiras, ${ }^{5}$ a caracterização entre mesorregiões com produção mais e menos modernizadas. Para tanto, foram utilizadas informações do Censo Agropecuário (2006) e dados da Produção Agrícola Municipal (PAM),

5. De acordo com a classificação do IBGE, o estado de Minas Gerais está dividido em 12 mesorregiões: 01 - Noroeste de Minas; 02 - Norte de Minas; 03 - Jequitinhonha; 04 - Vale do Mucuri; 05 - TMAP - Triângulo Mineiro e Alto Paranaíba; 06 - Central Mineira; 07 - Metropolitana de Belo Horizonte; 08 - Vale do Rio Doce; 09 - Oeste de Minas; 10 - Sul e Sudoeste de Minas; 11 - Campo das Vertentes; e 12 - Zona da Mata. para o mesmo ano. As variáveis que indicaram a presença ou não de modernização nas mesorregiões foram: número de máquinas e implementos agrícolas existentes nos estabelecimentos agropecuários (unidades); número de estabelecimentos agropecuários com tratores (unidades); número de tratores existentes nos estabelecimentos agropecuários (unidades); hectares por tratores; quantidade produzida por hectare; área total por números de estabelecimentos.

Posteriormente, a partir da tabulação dessas variáveis, foi possível agrupar as mesorregiões em mais e menos modernizadas, bem como a participação das culturas selecionadas, café, cana e milho, nestas mesorregiões. O Quadro 1 sintetiza as mesorregiões já selecionadas considerando como mais e menos modernizadas para café, cana-de-açúcar e milho. As mesorregiões mais modernizadas selecionadas foram: TMAP e Noroeste de Minas; já as menos modernizadas selecionadas foram: Jequitinhonha, Vale do Mucuri, Vale do Rio Doce e Zona da Mata.

Para fins de análise, identifica-se, também, segundo a Fundação João Pinheiro (www.fjp.mg.gov.br), diferença expressiva entre as mesorregiões mineiras em relação à participação no PIB e no PIB per capita, diferenças que impactam a dinâmica do mercado de trabalho. Assim, as análises reforçaram a segmentação de mesorregiões mais modernizadas e com maior PIB per capita (TMAP e Noroeste de Minas) e de outro, classificadas como as mesorregióes mais pobres e com menor PIB per capita (caso da mesorregião do Jequitinhonha e Vale do Mucuri), e intermediária em relação ao PIB per capita, situação em que se enquadram o Vale do Rio Doce e Zona da Mata e levou a realizar as análises nas mesorregióes menos modernizadas nesses dois agrupamentos. 
Quadro 1. Mesorregiões mais e menos modernizadas selecionadas em Minas Gerais

\begin{tabular}{|c|c|c|}
\hline Modernização & Culturas & Mesorregiões \\
\hline Mais modernizadas & \multirow{3}{*}{ Café, cana e milho } & $\begin{array}{l}01 \text { - Noroeste de Minas } \\
05 \text { - Triângulo Mineiro e Alto Paranaíba }\end{array}$ \\
\hline \multirow{2}{*}{ Menos modernizadas } & & $\begin{array}{l}03 \text { - Jequitinhonha } \\
04 \text { - Vale do Mucuri }\end{array}$ \\
\hline & & $\begin{array}{l}08 \text { - Vale do Rio Doce } \\
12 \text { - Zona da Mata }\end{array}$ \\
\hline
\end{tabular}

Fonte: IBGE. Elaboração própria.

\section{Metodologia}

A adoção de um índice sintético de qualidade do emprego para o ordenamento e a comparação dos grupos de ocupações agrícolas da PEA rural e urbana visa a, por meio de um único número, apresentar a contribuição conjunta das diferentes variáveis utilizadas para a aferição de alguns aspectos que seriam desejáveis em qualquer tipo de trabalho. Tal índice se mostra como uma forma sintética de expressar as informações originais dos indicadores (KAGEYAMA; REHDER, 1993; BALSADI, 2000).

Obviamente, o conceito de qualidade do emprego pode variar segundo diversas perspectivas. $\mathrm{O}$ que se pretende é, a partir das variáveis selecionadas do IBGE, mensurar os efeitos de alguns itens relativamente consensuais sobre a qualidade do emprego, como o não uso de trabalho infantil, a jornada regular semanal, a carteira assinada, a contribuição previdenciária, o rendimento do trabalhador e o recebimento de alguns auxílios.

A partir da referida proposta, trabalhou-se com os Censos Demográficos de 2000 e 2010, utilizando o software PASW ${ }^{\circledast}$ versão 18 para processamento dos microdados dos CD/IBGE e, para outras tabulações e ajustes, o Excel $^{\circledR} 2010$ foi usado.

Inicialmente, buscou-se criar um quadro com as variáveis de referência com a finalidade de gerar as sintaxes e filtros necessários para a construção dos índices, como as variáveis peso, estado de Minas Gerais, mesorregião, domicílio, atividades agrícolas, código da ocupação e posição na ocupação.

Para avaliar a evolução da qualidade do emprego com IQE e a partir dos microdados dos Censos Demográficos de 2000 e 2010, utilizou-se a metodologia descrita por Kageyama e Rehder (1993) e adaptada por Balsadi (2000, 2007). Especificamente, o presente artigo se baseou na proposta de Balsadi (2007, p. 41), em que os indicadores simples são:

- \% Empregado não infantil: percentual de empregados com idade acima de 15 anos (Ninf), o que representa a proporção de trabalho não infantil empregada;

- \% Jornada de empregado: percentual de empregados com jornada semanal de até 44 horas (Jorn), o que corresponde à participação dos empregados sem sobretrabalho;

- \% Carteira assinada: percentual de empregados com carteira assinada (Cart);

- \% Contribuinte da Previdência Social: percentual de empregados que são contribuintes com a previdência social (Prev);

- \% de Alfabet.: percentual de empregados considerados alfabetizados ou com até um ano de estudo;

- \% de Alfabet. com até oito anos de estudos: percentual de empregados com até oito anos de estudos (fx1_anosest), incluindo os não alfabetizados;

- \% de Alfabet. com mais de oito anos de estudos: percentual de empregados com mais de oito anos de estudos (f×2_asosest);

- Rendimento mensal em R\$: valor em reais do rendimento do grupo estudado (data referência de 2000 atualizada pelo INPC para data de referência de 2010);

- \%Npobreza: percentual de trabalhadores com remuneração acima de 1 salário mínimo (data referência de 2000 atualizada pelo INPC para data de referência de 2010).

Desses indicadores, o rendimento médio mensal precisou ser padronizado para variar de 0 a 100 , segundo a fórmula 1 : 
068 - Qualidade do Emprego nas Culturas de Café, Cana-de-açúcar e Milho: estudo comparativo 2000/2010 entre mesorregiões de Minas Gerais

$$
\frac{(\text { "Valor médio" - "Valor mínimo") }}{(\text { "Valor máximo" - "Valor mínimo") }} \cdot 100
$$

Em que o valor mínimo e o valor máximo são, respectivamente, os valores mínimo e máximo dos rendimentos encontrados em toda a série, possibilitando a comparação intertemporal. Para dar andamento aos cálculos, atualizou-se a data referência de 2000 para data de referência de 2010, a partir do INPC/IBGE. Após algumas análises introdutórias, verificou-se que a curva de rendimentos, em todos os casos, apresentava vários valores mínimos (inclusive zeros) e máximos (muito discrepantes) que poderiam distorcer os cálculos. Da mesma forma que encontrado em Teixeira (2015), foi eliminado $2 \%$ de cada extremidade, ficando a amostra com $96 \%$ dos dados do censo. Dessa forma, realizou-se o cálculo da renda média e, consequentemente, da renda padronizada.

A construção dos indicadores parciais foi feita a partir do cálculo das médias aritméticas dos indicadores originais, no sentido de captar três dimensões da qualidade do emprego, que estão relacionadas com o grau de formalização do trabalho (IND_FORM), o rendimento salarial obtido no trabalho principal (IND_REND) e o indicador de educação (IND_EDUC). Assim, os três indicadores parciais foram propostos originalmente Balsadi (2007), da seguinte forma:

$I N D_{-} F O R M=\frac{(\text { Ninf }+ \text { Jorn }+ \text { Cart }+ \text { Prev })}{4}$

[indica o grau de formalização do trabalho]

$I N D_{-} E D U C=\frac{\left(\text { Alfabetiz }+f x 1 \_ \text {anosest }+f x 2 \_ \text {anosest }\right)}{3}$

[agrega as variáveis tempo de estudo para os empregados]

$I N D \_R E N D=\frac{(\text { Rend padronizado }+N p o b)}{2}$

[agrega as duas variáveis de rendimento]

E, para a obtenção do valor do IQE, elaborou-se o cálculo a partir das médias ponderadas dos indicadores parciais. De modo simplificado, a proposta inicial do IQE foi apresentada levando-se em consideração cada indicador parcial com o mesmo peso.

$I Q E=\frac{\left(I N D_{-} F O R M+I N D_{-} E D U C+I N D_{-} R E N D\right)}{3}$
Para melhorar a estrutura dos pesos do IQE, Balsadi (2007) apresentou uma proposta de definição diferenciada de pesos para cada indicador a partir de uma técnica de multicritérios com base no método Macbeth (Measuring Attractiveness by a Categorical Based Evoluation Technique). Da mesma forma que Teixeira (2015) e levando-se em consideração a adaptação da metodologia do cálculo do IQE, bem como ponderando-se os indicadores parciais e o IQE a partir do método Macbeth, utiliza-se a proposta já avaliada e consolidada de cálculo com os pesos que priorizam certas condições sociais mais relevantes para a determinação da qualidade do emprego. Diante disso, o presente estudo dá continuidade ao processo de pesquisa ajustado e testado por Balsadi (2007) e Teixeira (2015), baseando-se nas descobertas e conclusões apresentadas. Assim sendo, os indicadores parciais e o indicador do IQE com os devidos pesos estão abaixo apresentados, os quais foram adotados ao longo do trabalho.

$I N D_{-} F O R M=\frac{(0,24+0,12+0,34+0,30)}{4}$

[indica o grau de formalização do trabalho]

$I N D_{-} E D U C=\frac{(0,19+0,36+0,45)}{3}$

[agrega as variáveis tempo de estudo para os empregados]

$I N D \_R E N D=\frac{(0,40+0,60)}{2}$

[agrega as duas variáveis de rendimento]

$I Q E=\frac{(0,34+0,25+0,41)}{3}$

Como os indicadores originais não serão padronizados em função dos máximos e mínimos, com exceção do rendimento (mas serão levados em consideração os valores da série toda), o IQE obtido é passível de comparação intertemporal. Para essa comparação, ainda de acordo com Kageyama e Rehder (1993) e Balsadi (2000), trabalha-se com a ideia de progresso relativo (PR), calculado pela seguinte fórmula:

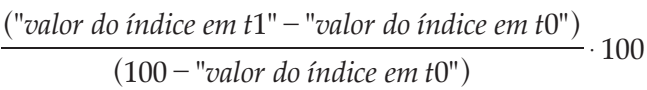

O resultado final pode ser entendido a partir da compreensão que o denominador mostra o máximo 
crescimento que seria possível a partir do ano inicial (progresso possível), e o numerador indica o crescimento obtido de fato no período considerado (progresso efetivo). A razão entre os dois valores compreende a velocidade relativa da melhoria nas condições e qualidade do trabalho.

É importante ressaltar que a modernização beneficiou empregos mais qualificados. Para o presente estudo, propõe-se a classificação dos empregados em qualificados e não qualificados nas culturas escolhidas, considerando o código de ocupação do IBGE dos Censos Demográficos de 2000 e 2010. Ao todo, trabalhou-se com aproximadamente $95 \%$ dos empregos que foram divididos em: empregos não qualificados, com o código 6229 (trabalhadores agrícolas) em 2000 e o 9211 (Trabalhadores Elementares da Agricultura); para empregos qualificados há os códigos 6410 (Trabalhadores da Mecanização Agropecuária), 7825 (Condutores de Veículos Sobre Rodas) e 7820 (Condutores e Operadores Polivalentes) para 2000 e os códigos 6111 (Agricultores e Trabalhadores Qualificados) e 8341 (Operadores de Máquinas Agrícolas e Florestais) para 2010.

\section{Resultados e discussão}

\subsection{Análise das mesorregiões TMAP e Noroeste de Minas (01 e 05): mais modernizadas nas culturas de café, cana e milho}

Os dados da Tabela 2 evidenciam o universo dos empregados agrícolas qualificados e não qualificados, com domicílios urbano e rural, para as mesorregiões
TMAP e Noroeste de Minas, entre 2000 e 2010. Pode-se observar que houve queda substantiva no estoque de empregados ao longo da década, tanto o emprego assalariado quanto o não qualificado agrícola urbano e rural. No caso dos empregados agrícolas urbanos, o efetivo passou de 26.762, em 2000, para 13.606, em 2010 (decréscimo de 13.156 empregos, equivalente a -49\%) e, para os empregados agrícolas não qualificados rurais, passou de 7.372, em 2000, para 2.545, em 2010 (recuo de 4.827 empregos, equivalente a $-65 \%$ ).

Entretanto, essa variação (Tabela 2) não se mostrou de forma homogênea quando avaliamos sob o ponto de vista do emprego qualificado e não qualificado. $\mathrm{O}$ emprego qualificado, tanto para residentes com domicílio urbano quanto para aqueles com domicílio rural, apresentou aumento: os empregados rurais qualificados cresceram de 1.312, em 2000, para 2.220, em 2010 (aumento de 69\%), e os empregados urbanos qualificados cresceram de 2.318, em 2000, para 5.342, em 2010 (aumento de 130\%).

Diante disso, a Tabela 2 demostra, de forma resumida, que, nas culturas de café, cana-de-açúcar e milho das mesorregiões consideradas mais modernizadas (mesorregiões TMAP e Noroeste de Minas), houve queda significativa no número de empregos não qualificados para os assalariados agrícolas, principalmente para os empregados com domicílio urbano, além de um aumento do número de empregos qualificados, cujo saldo final é negativo.

A Tabela 3 demonstra a evolução da qualidade do emprego (medido pelo IQE) dos assalariados qualificados nas culturas estabelecidas dos empregados residentes nas áreas urbanas e rurais das mesorregiões TMAP e Noroeste de Minas, entre 2000 e 2010. Pode-se observar, nessa tabela, que as condições de traba-

Tabela 2. Quadro resumo da quantidade de emprego assalariado agrícola qualificado e agrícola não qualificado, nas culturas do café, cana-de-açúcar e milho das mesorregiões TMAP e Noroeste de Minas entre 2000 e 2010

\begin{tabular}{|c|c|c|c|c|c|c|c|}
\hline \multirow[b]{2}{*}{ Atividade } & \multirow[b]{2}{*}{ Domicílio } & \multirow{2}{*}{$\begin{array}{c}\text { Censo } \\
2000\end{array}$} & \multirow{2}{*}{$\begin{array}{c}\text { Censo } \\
2010\end{array}$} & \multirow{2}{*}{$\begin{array}{c}\text { Var } \\
\text { (Absoluta) }\end{array}$} & \multirow{2}{*}{$\begin{array}{l}\text { Var } \\
(\%)\end{array}$} & \multicolumn{2}{|c|}{ \% de Participação } \\
\hline & & & & & & $\begin{array}{c}\text { Censo } \\
2000\end{array}$ & $\begin{array}{l}\text { Censo } \\
2010\end{array}$ \\
\hline \multirow{2}{*}{ Agrícola - emprego qualificado } & Urbano & 2.318 & 5.342 & 3.024 & $130 \%$ & $64 \%$ & $71 \%$ \\
\hline & Rural & 1.312 & 2.220 & 908 & $69 \%$ & $36 \%$ & $29 \%$ \\
\hline \multirow{2}{*}{ Agrícola - emprego não qualificado } & Urbano & 26.762 & 13.606 & -13.156 & $-49 \%$ & $78 \%$ & $84 \%$ \\
\hline & Rural & 7.372 & 2.545 & -4.827 & $-65 \%$ & $22 \%$ & $16 \%$ \\
\hline Subtotal agrícola urbano & & 29.080 & 18.948 & -10.132 & $-35 \%$ & $77 \%$ & $80 \%$ \\
\hline Subtotal agrícola rural & & 8.684 & 4.765 & -3.919 & $-45 \%$ & $23 \%$ & $20 \%$ \\
\hline
\end{tabular}

Fonte: Elaboração própria com base nos microdados do IBGE, Censos Demográficos de 2000 e 2010. 
070 - Qualidade do Emprego nas Culturas de Café, Cana-de-açúcar e Milho: estudo comparativo 2000/2010 entre mesorregiões de Minas Gerais

lho dos assalariados qualificados, residentes tanto no meio urbano quanto no rural, experimentaram queda. No caso dos residentes urbanos, o indicador passou de 69,0\%, em 2000, para 62,9\%, em 2010. Quanto aos residentes rurais, a queda foi menor, de $68,1 \%$ para $66,5 \%$, no mesmo período. Em relação aos assalariados não qualificados, houve queda somente em relação ao número de residentes urbanos (de 58,4\%, em 2000, para $57,4 \%$, em 2010). No que tange aos empregados não qualificados residentes rurais, foi apurada melhoria da qualidade do emprego, pois o IQE passou de $56,6 \%$, em 2000, para 59,1\%, em 2010. Resumidamente, os dados da Tabela 3 sinalizam que, no grupo de mesorregiões mais modernas e economicamente mais dinâmicas, a qualidade das condições de trabalho dos assalariados de cana-de-açúcar, café e milho, de forma geral, piorou, exceto para o grupo de não qualificados residentes no meio rural.

Esse registro mais geral da Tabela 3 pode ser explicado pela redução generalizada do indicador parcial de renda - Ind_Renda (apenas no caso dos assalariados não qualificados rurais é que essa redução foi menos expressiva), quando comparado aos demais, e em todas as situações, os indicadores parciais de formalização (Ind_Formal) e de educação (Ind_Educ) aumentaram. De modo geral, o indicador parcial de renda
(Ind_Renda) foi afetado negativamente pela queda generalizada do indicador simples de percentual de empregados que ganham acima de um salário mínimo (\% Npobreza), verificando-se, na década, um aumento do número de empregados que passaram a ganhar até um salário mínimo. O indicador formalização foi afetado por um aumento no indicador simples de jornada de trabalho (\% Jornada de Trabalho), que identifica uma melhoria nas condições de trabalho, isto é, aumentou o percentual de empregados com jornada semanal de até 44 horas. Quanto aos empregados qualificados, houve diminuição do percentual de empregados com carteira assinada e, consequentemente, uma diminuição dos contribuintes com a Previdência Social.

Essas observações podem indicar que o aumento do contingente de assalariados qualificados tem sido acompanhado das seguintes situações: i) decréscimo dos indicadores de renda, formalização (carteira assinada) e previdência e ii) melhoria no nível educacional. $\mathrm{O}$ que esse quadro revela considerando os dados analisados? Que os trabalhadores estão mais qualificados e mais escolarizados; no entanto, as demais condições de trabalho pioraram. Poder-se-ia sugerir que os trabalhadores assalariados nas três culturas sob análise estão aceitando essa situação premidos pelo desemprego gerado pelo próprio processo que elevou

Tabela 3. Indicadores Parciais (\%) e Índice de Qualidade do Emprego (\%) para os empregados das mesorregiões TMAP e Noroeste de Minas (01 e 05), mais modernizadas nas culturas de café, cana-de-açúcar e milho

\begin{tabular}{|c|c|c|c|c|c|c|c|c|}
\hline \multirow{3}{*}{$\begin{array}{c}\text { Indicadores Parciais e } \\
\text { IQE - Índice de Qualidade do Emprego }\end{array}$} & \multicolumn{4}{|c|}{ Empregado Assalariado Qualificado } & \multicolumn{4}{|c|}{$\begin{array}{c}\text { Empregado Assalariado não } \\
\text { Qualificado }\end{array}$} \\
\hline & \multicolumn{2}{|c|}{ Urbano } & \multicolumn{2}{|c|}{ Rural } & \multicolumn{2}{|c|}{ Urbano } & \multicolumn{2}{|c|}{ Rural } \\
\hline & $\begin{array}{l}\text { Censo } \\
2000 \\
\end{array}$ & $\begin{array}{l}\text { Censo } \\
2010 \\
\end{array}$ & $\begin{array}{l}\text { Censo } \\
2000 \\
\end{array}$ & $\begin{array}{l}\text { Censo } \\
2010 \\
\end{array}$ & $\begin{array}{l}\text { Censo } \\
2000 \\
\end{array}$ & $\begin{array}{l}\text { Censo } \\
2010 \\
\end{array}$ & $\begin{array}{l}\text { Censo } \\
2000 \\
\end{array}$ & $\begin{array}{c}\text { Censo } \\
2010 \\
\end{array}$ \\
\hline \% Empregado não infantil empregado & 99,0 & 98,9 & 100,0 & 98,9 & 98,2 & 98,8 & 96,9 & 99,1 \\
\hline \% Jornada de empregado & 27,6 & 47,7 & 24,4 & 52,8 & 39,4 & 52,9 & 33,5 & 54,3 \\
\hline$\%$ Carteira assinada & 79,3 & 76,2 & 79,0 & 74,7 & 64,0 & 68,2 & 57,2 & 63,5 \\
\hline \%Contribuinte previdência social & 80,8 & 78,1 & 80,0 & 75,6 & 66,1 & 69,9 & 58,2 & 64,7 \\
\hline IND_FORMAL & 78,3 & 78,8 & 77,8 & 78,2 & 69,9 & 74,2 & 64,2 & 71,3 \\
\hline Rendimento mensal em $\mathrm{R} \$^{*}$ & 672 & 831 & 675 & 814 & 453 & 639 & 458 & 659 \\
\hline$\%$ Npobreza & 96,3 & 68,1 & 94,9 & 75,4 & 65,9 & 50,6 & 67,8 & 57,0 \\
\hline Rendimento padronizado (\%) & 32,6 & 33,9 & 30,4 & 44,3 & 34,4 & 37,6 & 30,6 & 43,9 \\
\hline IND_RENDA & 70,8 & 54,4 & 69,1 & 62,9 & 53,3 & 45,4 & 53,0 & 51,8 \\
\hline$\%$ de alfabet. & 89,7 & 87,6 & 89,5 & 93,4 & 81,7 & 83,6 & 85,2 & 85,7 \\
\hline$\%$ de alfabet. com até 8 anos de estudos & 92,7 & 69,9 & 94,5 & 71,3 & 91,5 & 76,2 & 91,5 & 74,7 \\
\hline$\%$ de alfabet. com mais de 8 anos de estudos & 6,3 & 30,1 & 5,2 & 28,7 & 6,0 & 23,8 & 6,8 & 25,3 \\
\hline IND_EDUC & 53,3 & 55,3 & 53,3 & 56,3 & 51,2 & 54,0 & 52,2 & 54,6 \\
\hline IQE & 69,0 & 62,9 & 68,1 & 66,5 & 58,4 & 57,4 & 56,6 & 59,1 \\
\hline
\end{tabular}

* Rendimento médio mensal corrigido pelo INPC (IBGE) para 2010.

Fonte: Elaboração própria com base nos microdados do IBGE Censos Demográficos de 2000 e 2010. 
o número de qualificados e provocou a redução em maior proporção do contingente de não qualificados, ou seja, por estarem pressionados pela modernização (mecanização) agrícola.

Em relação ao aumento do indicador educação (Ind_Educ), esse pode ser explicado pela diminuição do número de empregados analfabetos e com até oito anos de estudos, seguida de um aumento no número de empregados com mais de oito anos de estudo (indicador simples de $\%$ de alfabetizados com mais de oito anos de estudos).

Sintetizando a Tabela 3, observa-se também que, no que se refere aos empregados assalariados qualificados urbanos e rurais e aos empregados assalariados não qualificados urbanos na mesorregião TMAP e Noroeste de Minas, houve uma diminuição das condições de trabalho (IQE) devido ao decréscimo acentuado do indicador renda, apesar do aumento dos indicadores formalidade e educação. Quanto aos empregados não qualificados rurais, o IQE não piorou, porque a queda do indicador renda não foi tão acentuada e, por isso, os aumentos dos indicadores formalização e educação foram capazes de contribuir, positivamente, para o indicador final.

Outros fatores que também podem ser ressaltados a partir da Tabela 3 são: apesar da queda do IQE no emprego qualificado (tanto no meio urbano quanto no rural), esse ainda apresenta qualidade superior ao emprego não qualificado; a qualidade do emprego qualificado rural em 2010 tornou-se melhor que a do emprego urbano (66,5\% rural qualificado contra 62,9\% urbano qualificado). Essa observação foi também verificada quanto aos empregados não qualificados, ou seja, o IQE dos empregados não qualificados com domicílio rural foi maior $(59,1 \%)$ do que o dos empre- gados não qualificados com domicílio urbano $(57,4 \%)$. Em outras palavras, as condições de trabalho dos residentes rurais, tanto qualificados como não qualificados, melhoraram nessa mesorregião em relação aos residentes urbanos.

Outra observação importante é a de que, mesmo com a maior qualidade do emprego para os empregados qualificados com domicílio rural, ao retomar a Tabela 2, verifica-se que essa qualidade se restringiu à uma pequena parcela de empregados que, em 2000, era de 1.312 empregados e, em 2010, passou para 2.220 empregados - na década, a variação foi de apenas 908 empregados.

\subsection{Análise das mesorregiões Jequitinhonha e Vale do Mucuri (03 e 04): \\ menos modernizadas nas culturas de café, cana-de-açúcar e milho, que apresentam baixo PIB per capita}

A Tabela 4 reúne dados dos empregados agrícolas qualificados e não qualificados com domicílio urbano e rural para as mesorregiões Jequitinhonha e Vale do Mucuri, para os anos de 2000 e 2010 . Pode-se observar uma significativa queda nos empregados assalariados não qualificados com domicílio urbano e do meio rural ao longo da década. Para os empregados agrícolas não qualificados com domicílio urbano, os empregos passaram de 9.263, em 2000, para 4.443, em 2010 (decréscimo de 4.820 empregos, equivalente a $-52 \%$ ). Quanto aos empregados agrícolas rurais, o estoque de 19.194 empregos, em 2000, caiu para 8.463, em 2010 (decréscimo de 10.731 empregos, $-56 \%$ ).

No que tange ao emprego qualificado, tanto para os empregados residentes com domicílio urbano quanto

Tabela 4. Quadro-resumo da quantidade de emprego assalariado agrícola qualificado e agrícola não qualificado, nas mesorregiões Jequitinhonha e Vale do Mucuri (03 e 04), de 2000 e 2010

\begin{tabular}{|c|c|c|c|c|c|c|c|}
\hline \multirow[b]{2}{*}{ Atividade } & \multirow[b]{2}{*}{ Domicílio } & \multirow{2}{*}{$\begin{array}{c}\text { Censo } \\
2000\end{array}$} & \multirow{2}{*}{$\begin{array}{c}\text { Censo } \\
2010\end{array}$} & \multirow{2}{*}{$\begin{array}{c}\text { Var } \\
\text { (Absoluta) }\end{array}$} & \multirow{2}{*}{$\begin{array}{l}\text { Var } \\
(\%)\end{array}$} & \multicolumn{2}{|c|}{ \% de participação } \\
\hline & & & & & & $\begin{array}{c}\text { Censo } \\
2000\end{array}$ & $\begin{array}{c}\text { Censo } \\
2010\end{array}$ \\
\hline \multirow{2}{*}{ Agrícola - emprego qualificado } & Urbano & 157 & 1.190 & 1.033 & $658 \%$ & $39 \%$ & $36 \%$ \\
\hline & Rural & 244 & 2.149 & 1.905 & $781 \%$ & $61 \%$ & $64 \%$ \\
\hline \multirow{2}{*}{ Agrícola - emprego não qualificado } & Urbano & 9.263 & 4.443 & -4.820 & $-52 \%$ & $33 \%$ & $34 \%$ \\
\hline & Rural & 19.194 & 8.463 & -10.731 & $-56 \%$ & $67 \%$ & $66 \%$ \\
\hline Subtotal agrícola urbano & & 9.420 & 5.633 & -3.787 & $-40 \%$ & $33 \%$ & $35 \%$ \\
\hline Subtotal agrícola rural & & 19.438 & 10.612 & -8.826 & $-45 \%$ & $67 \%$ & $65 \%$ \\
\hline
\end{tabular}

Fonte: Elaboração própria com base nos microdados do IBGE Censos Demográficos de 2000 e 2010. 
072 Qualidade do Emprego nas Culturas de Café, Cana-de-açúcar e Milho: estudo comparativo 2000/2010 entre mesorregiões de Minas Gerais

para os com domicílio rural, houve um aumento substancial no número de assalariados (os empregados rurais qualificados): cresceu de 244, em 2000, para 2.149, em 2010 (aumento de 781\%), e os empregados urbanos qualificados cresceram de 157, em 2000, para 1.190, em 2010 (+658\%).

Mesmo com o expressivo aumento percentual do emprego qualificado, pelo fato de partir de um baixo volume em 2000, quando se analisa o volume total de emprego nessas duas mesorregiões entre 2000 e 2010, nota-se queda significativa no emprego agrícola urbano (-40\%) e no emprego agrícola rural (-45\%), em função da elevada queda no total de emprego não qualificado com domicílios rural e urbano (Tabela 4).

Portanto, nas culturas de café, cana-de-açúcar e milho nas mesorregiões consideradas menos modernizadas (Jequitinhonha e Vale do Mucuri), houve perda significativa no número de empregos não qualificados para os assalariados agrícolas e um aumento do número de empregos qualificados, principalmente com domicílio rural.

Já a Tabela 5 demonstra a evolução da qualidade do emprego (medido pelo IQE) nessas duas mesorregiões, classificada em assalariados qualificados e não qualificados, residentes nas áreas urbanas e rurais nas culturas analisadas. Pode-se observar, nessa tabela, que as condições de trabalho dos assalariados qualificados, residentes tanto no meio urbano quanto no rural, experimentaram um decréscimo. Para os residentes urbanos, o IQE passou de 53,7\%, em 2000, para $44,9 \%$, em 2010, e para os residentes rurais, passou de $55,6 \%$ para 47,3\% no mesmo período. Em relação aos assalariados não qualificados, ocorreu melhoria nas condições de trabalho. Para os assalariados residentes no meio urbano, o IQE passou de $38,8 \%$, em 2000, para $45,4 \%$, em 2010 , e quanto aos residentes rurais, no mesmo período, o IQE foi de $43,4 \%$ para $49,7 \%$. Resumidamente, os dados da Tabela 5 apontam que, no grupo de mesorregiões menos modernizadas, as condições de trabalho dos assalariados das culturas de café, cana-de-açúcar e milho pioraram para os trabalhadores qualificados e melhoraram para os trabalhadores não qualificados.

Esse registro contido na Tabela 5 pode ser explicado pela redução do indicador parcial renda (Ind_Renda) para os empregados assalariados qualificados com domicílios urbano e rural e pelo aumento do indicador parcial de renda (Ind_Renda) para os empregados assalariados não qualificados com domicílio urbano e rural. Esse indicador, por sua vez, foi afetado negativa-

Tabela 5. Indicadores Parciais (\%) e Índice de Qualidade do Emprego (\%) para os empregados das mesorregiões Jequitinhonha e Vale do Mucuri (03 e 04), menos modernizadas nas culturas do café, cana e milho, que apresentam baixo PIB per capita

\begin{tabular}{|c|c|c|c|c|c|c|c|c|}
\hline \multirow{3}{*}{$\begin{array}{c}\text { Indicadores Parciais e } \\
\text { IQE - Índice de Qualidade do Emprego }\end{array}$} & \multicolumn{4}{|c|}{ Empregado Assalariado Qualificado } & \multicolumn{4}{|c|}{$\begin{array}{c}\text { Empregado Assalariado não } \\
\text { Qualificado }\end{array}$} \\
\hline & \multicolumn{2}{|c|}{ Urbano } & \multicolumn{2}{|c|}{ Rural } & \multicolumn{2}{|c|}{ Urbano } & \multicolumn{2}{|c|}{ Rural } \\
\hline & $\begin{array}{c}\text { Censo } \\
2000\end{array}$ & $\begin{array}{c}\text { Censo } \\
2010\end{array}$ & $\begin{array}{c}\text { Censo } \\
2000\end{array}$ & $\begin{array}{c}\text { Censo } \\
2010\end{array}$ & $\begin{array}{c}\text { Censo } \\
2000\end{array}$ & $\begin{array}{c}\text { Censo } \\
2010\end{array}$ & $\begin{array}{c}\text { Censo } \\
2000\end{array}$ & $\begin{array}{l}\text { Censo } \\
2010\end{array}$ \\
\hline \% Empregado não infantil empregado & 100,0 & 98,7 & 100,0 & 97,0 & 94,8 & 97,4 & 94,6 & 98,0 \\
\hline$\%$ Jornada de empregado & 20,8 & 68,1 & 36,3 & 74,5 & 50,7 & 56,6 & 52,3 & 65,2 \\
\hline$\%$ Carteira assinada & 30,1 & 44,4 & 64,0 & 46,6 & 23,9 & 45,4 & 35,6 & 54,3 \\
\hline \% Contribuinte previdência social & 32,8 & 50,4 & 65,9 & 52,1 & 25,7 & 47,3 & 37,0 & 56,2 \\
\hline IND_FORMAL & 46,6 & 62,1 & 69,9 & 63,7 & 44,7 & 59,8 & 52,2 & 66,7 \\
\hline Rendimento mensal em $\mathrm{R}^{*}$ & 533 & 423 & 476 & 417 & 290 & 448 & 312 & 448 \\
\hline$\%$ Npobreza & 83,9 & 18,1 & 63,6 & 25,2 & 29,0 & 24,2 & 35,7 & 25,8 \\
\hline Rendimento padronizado $(\%)$ & 26,0 & 38,5 & 26,6 & 38,1 & 28,4 & 36,3 & 31,6 & 44,8 \\
\hline IND_RENDA & 60,7 & 26,2 & 48,8 & 30,4 & 28,7 & 29,0 & 34,1 & 33,4 \\
\hline$\%$ de alfabet. & 92,6 & 74,2 & 59,4 & 79,7 & 63,2 & 74,3 & 61,7 & 79,2 \\
\hline$\%$ de alfabet. com até 8 anos de estudos & 91,6 & 75,2 & 100,0 & 80,3 & 92,4 & 73,6 & 94,7 & 76,3 \\
\hline$\%$ de alfabet. com mais de 8 anos de estudos & 3,3 & 24,8 & - & 19,7 & 4,6 & 26,4 & 1,9 & 23,7 \\
\hline IND_EDUC & 52,1 & 52,3 & 47,3 & 52,9 & 47,3 & 52,5 & 46,7 & 53,2 \\
\hline IQE & 53,7 & 44,9 & 55,6 & 47,3 & 38,8 & 45,4 & 43,4 & 49,7 \\
\hline
\end{tabular}

* Rendimento médio mensal corrigido pelo INPC (IBGE) para 2010.

Fonte: Elaboração própria com base nos microdados do IBGE Censos Demográficos de 2000 e 2010. 
mente pela queda generalizada do indicador simples de percentual de empregados que ganham acima de um salário mínimo (\%Npobreza). Verificou-se que, na década, houve diminuição do número de empregados que passaram a ganhar mais que um salário mínimo, o que pode ser verificado pelos valores de rendimento médios mensais, que eram em torno de um salário mínimo. Isso significa que os trabalhadores qualificados que, na década de 2000, ganhavam valores acima do salário mínimo, na década de 2010, tiveram esses valores reduzidos a patamares similares aos salários pagos aos trabalhadores não qualificados.

Em termos de formalização (Tabela 5), de modo geral, os indicadores parciais de formalização (Ind_Formal) aumentaram, com exceção do emprego assalariado qualificado rural, indicador que pode ser explicado pela diminuição do percentual de carteira assinada e, consequentemente, do percentual de contribuintes da Previdência Social. Ainda, houve aumento do indicador parcial de educação (Ind_Educ) em todos os casos, o que pode ser explicado pela diminuição do número de empregados analfabetos com até oito anos de estudos, seguido de um aumento no número de empregados com mais de oito anos de estudo (indicador simples de \% de alfabetizados com mais de oito anos de estudos).

Ainda, analisando-se a Tabela 5, percebe-se que os empregados assalariados qualificados (urbanos e rurais) apresentaram diminuição do IQE devido à diminuição acentuada do indicador renda, apesar do aumento do indicador educação. Já para os empregados qualificados urbanos, houve aumento da formalização e, para os empregados qualificados rurais, a redução na formalização contribuiu para a queda do IQE. Nesse caso, o empregado assalariado qualificado rural pode ter sido o mais prejudicado na década, visto que houve aumento do índice de educação acompanhado pela diminuição do indicador renda e diminuição do indicador formalização.

\subsection{Análise das mesorregiões Vale do Rio Doce e Zona da Mata (8 e 12) menos modernizadas nas culturas de café, cana-de-açúcar e milho com PIB per capita intermediário}

A análise dos dados da Tabela 6 permite visualizar o perfil dos empregados agrícolas qualificados e não qualificados, com domicílios urbano e rural, para as mesorregiões Vale do Rio Doce e Zona da Mata, entre 2000 e 2010. Pode-se observar que houve forte diminuição do emprego assalariado agrícola não qualificado com domicílios urbano e rural ao longo da década. No que concerne aos empregados agrícolas não qualificados urbanos, o número de empregos passou de 36.738, em 2000, para 10.949, em 2010 (decréscimo de 25.789 empregos, equivalente a $-70 \%$ ), enquanto o estoque de empregados não qualificados rurais passou de 53.717 empregos, em 2000, para apenas 13.825 empregos, em 2010 (decréscimo de 39.892 empregos, ou 74\%).

Em relação ao emprego qualificado (Tabela 6), tanto para residentes com domicílio urbano quanto rural, destaca-se o aumento expressivo do número de assalariados, pois a quantidade de empregados rurais qualificados cresceu de 349, em 2000, para 18.877, no ano de 2010 (aumento de 5.309\%), e a quantidade de empregados urbanos qualificados cresceu de 348 empregos, em 2000, para 9.308, em 2010 (elevação de $2.575 \%$ ). Dessa forma, a maior participação dos empre-

Tabela 6. Resumo da quantidade de emprego assalariado agrícola qualificado e agrícola não qualificado, nas mesorregiões Vale do Rio Doce e Zona da Mata (08 e 12), entre 2000 e 2010

\begin{tabular}{|c|c|c|c|c|c|c|c|}
\hline \multirow[b]{2}{*}{ Atividade } & \multirow[b]{2}{*}{ Domicílio } & \multirow{2}{*}{$\begin{array}{c}\text { Censo } \\
2000\end{array}$} & \multirow{2}{*}{$\begin{array}{c}\text { Censo } \\
2010\end{array}$} & \multirow{2}{*}{$\begin{array}{c}\text { Var } \\
\text { (Absoluta) }\end{array}$} & \multirow{2}{*}{$\begin{array}{l}\text { Var } \\
(\%)\end{array}$} & \multicolumn{2}{|c|}{$\%$ de participação } \\
\hline & & & & & & $\begin{array}{c}\text { Censo } \\
2000\end{array}$ & $\begin{array}{c}\text { Censo } \\
2010\end{array}$ \\
\hline \multirow{2}{*}{ Agrícola - emprego qualificado } & Urbano & 348 & 9.308 & 8.960 & $2575 \%$ & $50 \%$ & $33 \%$ \\
\hline & Rural & 349 & 18.877 & 18.528 & $5309 \%$ & $50 \%$ & $67 \%$ \\
\hline \multirow{2}{*}{ Agrícola - emprego não qualificado } & Urbano & 36.738 & 10.949 & -25.789 & $-70 \%$ & $41 \%$ & $44 \%$ \\
\hline & Rural & 53.717 & 13.825 & -39.892 & $-74 \%$ & $59 \%$ & $56 \%$ \\
\hline Subtotal agrícola urbano & & 37.086 & 20.257 & -16.829 & $-45 \%$ & $41 \%$ & $38 \%$ \\
\hline Subtotal agrícola rural & & 54.066 & 32.702 & -21.364 & $-40 \%$ & $59 \%$ & $62 \%$ \\
\hline
\end{tabular}

Fonte: Elaboração própria com base nos microdados do IBGE Censos Demográficos de 2000 e 2010. 

Minas Gerais

gos, tanto no substancial crescimento como na queda, foi dos empregados com domicílio rural.

Os dados mostram, de forma resumida, que, nas culturas de café, cana-de-açúcar e milho nas mesorregiões consideradas menos modernizadas (Vale do Rio Doce e Zona da Mata), houve significativa perda no número de empregos não qualificados para os assalariados agrícolas e aumento bem representativo do número de empregos qualificados, mas que não compensou o saldo final, que é de queda no número absoluto de empregos.

Já a Tabela 7 demonstra a evolução da qualidade do emprego (medida pelo IQE) dos assalariados qualificados e não qualificados. Pode-se observar, nessa tabela, que o índice de qualidade do emprego dos assalariados qualificados, residentes, tanto no meio urbano quanto no rural, teve decréscimo: no caso dos residentes urbanos, o IQE passou de $57,7 \%$, em 2000, para 39,9\%, em 2010; enquanto para os residentes rurais, essa queda foi mais acentuada, de $61,3 \%$ para $36,6 \%$, no mesmo período. Em relação aos assalariados não qualificados, houve também queda do indicador, tanto para os residentes urbanos (de $43,8 \%$, em 2000, para $38,5 \%$, em 2010) como para os residentes rurais (de $39,3 \%$, em 2000 , para $36,0 \%$, em 2010). Resumidamente, a obser- vação geral da Tabela 7 apontou que, no grupo de mesorregiões menos modernizadas com PIB per capita intermediário, a qualidade das condições de trabalho dos assalariados das três culturas piorou para todos os grupos.

Outros aspectos que merecem destaque (Tabela 7) são os baixos rendimentos médios recebidos pelos empregados nessa mesorregião e a queda da renda mensal média de 2000 para 2010 para quase todos os empregados (exceção dos empregados não qualificados com residência urbana). Em termos de formalização, de modo geral, os indicadores parciais de formalização (Ind_Formal) diminuíram para os empregados assalariados qualificados (urbano e rural), o que pode ser explicado pela queda do percentual de carteira assinada, consequentemente, também afetando negativamente o percentual de contribuição à Previdência.

Já a formalização dos empregados assalariados não qualificados (Tabela 7) apresentou pouca variação. Para os assalariados não qualificados com domicílio urbano, houve um aumento em pequena proporção e, para os assalariados não qualificados rurais, esse indicador diminuiu, embora em pequena proporção. Nesses casos, o indicador simples relevante, que influenciou o indicador parcial Ind_Formal, foi o aumento do per-

Tabela 7. Indicadores Parciais (\%) e Índice de Qualidade do Emprego (\%) para os empregados das mesorregiões Vale do Rio Doce e Zona da Mata (08 e 12), menos modernizados nas culturas de café, cana-de-açúcar e milho, com PIB per capita intermediário

\begin{tabular}{|c|c|c|c|c|c|c|c|c|}
\hline \multirow{3}{*}{$\begin{array}{c}\text { Indicadores Parciais e } \\
\text { IQE - Índice de Qualidade do Emprego }\end{array}$} & \multicolumn{4}{|c|}{ Empregado Assalariado Qualificado } & \multicolumn{4}{|c|}{$\begin{array}{c}\text { Empregado Assalariado não } \\
\text { Qualificado }\end{array}$} \\
\hline & \multicolumn{2}{|c|}{ Urbano } & \multicolumn{2}{|c|}{ Rural } & \multicolumn{2}{|c|}{ Urbano } & \multicolumn{2}{|c|}{ Rural } \\
\hline & $\begin{array}{l}\text { Censo } \\
2000\end{array}$ & $\begin{array}{l}\text { Censo } \\
2010\end{array}$ & $\begin{array}{l}\text { Censo } \\
2000\end{array}$ & $\begin{array}{c}\text { Censo } \\
2010\end{array}$ & $\begin{array}{l}\text { Censo } \\
2000\end{array}$ & $\begin{array}{l}\text { Censo } \\
2010\end{array}$ & $\begin{array}{l}\text { Censo } \\
2000\end{array}$ & $\begin{array}{l}\text { Censo } \\
2010\end{array}$ \\
\hline \% Empregado não infantil empregado & 100,00 & 97,9 & 100,0 & 96,1 & 94,5 & 97,6 & 93,3 & 95,6 \\
\hline$\%$ Jornada de empregado & 18,1 & 60,9 & 19,3 & 54,1 & 43,2 & 61,4 & 44,6 & 63,7 \\
\hline$\%$ Carteira assinada & 49,3 & 16,1 & 65,5 & 10,9 & 13,6 & 16,9 & 10,1 & 8,7 \\
\hline \%Contribuinte previdência social & 57,2 & 25,0 & 69,1 & 28,4 & 17,1 & 22,5 & 16,1 & 18,8 \\
\hline IND_FORMAL & 60,1 & 43,8 & 69,3 & 41,8 & 37,6 & 43,3 & 36,0 & 39,2 \\
\hline Rendimento mensal em $\mathrm{R}^{*}$ & 663 & 439 & 598 & 358 & 356 & 413 & 353 & 336 \\
\hline$\%$ Npobreza & 85,7 & 18,3 & 71,9 & 11,7 & 52,2 & 17,2 & 41,6 & 15,1 \\
\hline Rendimento padronizado (\%) & 14,9 & 43,3 & 41,6 & 36,9 & 34,9 & 38,2 & 26,7 & 33,6 \\
\hline IND_RENDA & 57,4 & 28,3 & 59,8 & 21,8 & 45,3 & 25,6 & 35,7 & 22,5 \\
\hline$\%$ de alfabet. & 92,3 & 81,7 & 88,8 & 84,4 & 74,8 & 80,7 & 75,4 & 83,1 \\
\hline$\%$ de alfabet. com até 8 anos de estudos & 86,4 & 77,3 & 93,4 & 80,4 & 92,2 & 80,2 & 92,8 & 79,2 \\
\hline$\%$ de alfabet. com mais de 8 anos de estudos & 13,6 & 22,7 & 4,9 & 19,6 & 5,2 & 19,8 & 4,4 & 20,8 \\
\hline IND_EDUC & 54,8 & 53,6 & 52,7 & 53,8 & 49,8 & 53,1 & 49,7 & 53,7 \\
\hline IQE & 57,7 & 39,9 & 61,3 & 36,6 & 43,8 & 38,5 & 39,3 & 36,0 \\
\hline
\end{tabular}

* Rendimento médio mensal corrigido pelo INPC (IBGE) para 2010.

Fonte: Elaboração própria com base nos microdados do IBGE Censos Demográficos de 2000 e 2010. 
centual de empregados com jornada de trabalho até $44 \mathrm{~h} /$ semanais.

O indicador parcial de educação (Ind_Educ) apresentou modesto aumento em quase todos os casos (exceção dos empregados assalariados qualificados urbanos, que diminuíram, influenciados pelo indicador simples do percentual de alfabetizados). De modo geral, o aumento desse indicador de educação pode ser explicado pela maior participação do número de empregados com mais de oito anos de estudo. Outro fato que merece destaque em relação a esse indicador é que o percentual de alfabetizados diminuiu tanto para o empregado assalariado qualificado urbano (de $92,3 \%$, em 2000 , para $81,7 \%$, em 2010 ) quanto para o empregado assalariado qualificado rural (de $88,8 \%$, em 2000 , para $84,4 \%$, em 2010). Tais dados apontam que empregados assalariados não qualificados e não alfabetizados, na década de 2000, foram empregados como assalariados qualificados em 2010 (Tabela 7).

De forma geral, pode-se verificar, pela Tabela 7, que os empregados assalariados qualificados (urbanos e rurais) apresentaram queda do índice de qualidade do emprego (IQE) devido à diminuição acentuada do indicador parcial de renda, do indicador de formalização e do indicador parcial de educação. Outra situação que deve ser destacada é o substancial aumento de 18.528 empregos assalariados qualificados com domicílio rural, na década, para essas mesorregiões, equivalente a $5.309 \%$ (conforme Tabela 6). No entanto, esse maior volume não implicou na melhoria do IQE para essa categoria.

$\mathrm{O}$ aumento da porcentagem dos empregados apenas alfabetizados (Tabela 7) fortalece a ideia de que vários empregados assalariados não qualificados começaram a ocupar empregos qualificados em piores condições de formalidade e com rendas mais baixas, $\mathrm{o}$ que pode ser comprovado pela diminuição dos valores de rendimento médio mensal em Reais, em ambos os tipos de domicílios.

\subsection{Análise comparativa do IQE diferenciando os três grupos de mesorregiões}

A Tabela 8 apresenta evolução da qualidade do emprego (medido pelo IQE) para as mesorregiões consideradas mais modernizadas TMAP (01 e 05) quando comparadas às mesorregiões consideradas menos modernizadas, Jequitinhonha e Vale do Mucuri (03 e 04), e Vale do Rio Doce e Zona da Mata (08 e 12).

A análise do IQE na Tabela 8 foi realizada avaliando os empregados qualificados e não qualificados (residentes no meio urbano e no rural). Analisando-se a qualidade do emprego, é possível perceber que os maiores índices de IQE, para 2010, encontram-se nas mesorregiões mais modernizadas e se referem ao emprego qualificado, tanto para aqueles com domicílio urbano como rural. O IQE do emprego qualificado rural foi $66,5 \%$ nas mesorregiões TMAP e Noroeste de Minas, comparado a $47,3 \%$ nas mesorregiões Jequitinhonha e Vale do Mucuri, e apenas 36,6\% nas mesorregiões Vale do Rio Doce e Zona da Mata. Já para o emprego qualificado urbano, o IQE foi de 62,9\% nas mesorregiões TMAP e Noroeste de Minas, contra $44,9 \%$ nas mesorregiões Jequitinhonha e Vale do Mucuri e 39,9\% no Vale do Rio Doce e na Zona da Mata.

Para os empregados não qualificados, as condições de trabalho foram piores que a dos empregados qualificados. Para os não qualificados urbanos, o IQE foi de 57,4\% nas mesorregiões TMAP e Noroeste de Minas, contra $45,4 \%$ nas mesorregiões Jequitinhonha

Tabela 8. Comparativo entre os indicadores IQE (\%) com os respectivos progressos relativos, diferenciando as mesorregiões TMAP e Noroeste de Minas (caracterizadas por alta modernização nas culturas de café, cana e milho) das de Jequitinhonha e Vale do Mucuri (caracterizadas por baixa modernização nas culturas de café, cana e milho, e PIB per capita baixo) e das mesorregiões Vale do Rio Doce e Zona da Mata (de baixa modernização nas culturas de café, cana e milho, e PIB per capita intermediário)

\begin{tabular}{|c|c|c|c|c|c|c|c|c|c|c|c|c|c|}
\hline \multirow{3}{*}{$\stackrel{\mathscr{\Xi}}{:}$} & \multirow{3}{*}{ Mesorregiões } & \multicolumn{6}{|c|}{ Empregado qualificado } & \multicolumn{6}{|c|}{ Empregado não qualificado } \\
\hline & & \multicolumn{3}{|c|}{ Urbano } & \multicolumn{3}{|c|}{ Rural } & \multicolumn{3}{|c|}{ Urbano } & \multicolumn{3}{|c|}{ Rural } \\
\hline & & $\begin{array}{c}\text { Censo } \\
2000\end{array}$ & $\begin{array}{c}\text { Censo } \\
2010\end{array}$ & $P R$ & $\begin{array}{c}\text { Censo } \\
2000\end{array}$ & $\begin{array}{c}\text { Censo } \\
2010\end{array}$ & $P R$ & $\begin{array}{c}\text { Censo } \\
2000\end{array}$ & $\begin{array}{c}\text { Censo } \\
2010 \\
\end{array}$ & $P R$ & $\begin{array}{c}\text { Censo } \\
2000\end{array}$ & $\begin{array}{c}\text { Censo } \\
2010\end{array}$ & $P R$ \\
\hline \multirow{3}{*}{ IQE } & TMAP e Noroeste de Minas (01 e 05) & 69,0 & 62,9 & $-20 \%$ & 68,1 & 66,5 & $-5 \%$ & 58,4 & 57,4 & $-2 \%$ & 56,6 & 59,1 & $6 \%$ \\
\hline & Jequitinhonha e Vale do Mucuri (03 e 04) & 53,7 & 44,9 & $-19 \%$ & 55,6 & 47,3 & $-19 \%$ & 38,8 & 45,4 & $11 \%$ & 43,4 & 49,7 & $11 \%$ \\
\hline & Vale do Rio Doce e Zona da Mata (08 e 12) & 57,7 & 39,9 & $-42 \%$ & 61,3 & 36,6 & $-64 \%$ & 43,8 & 38,5 & $-9 \%$ & 39,3 & 36,0 & $-5 \%$ \\
\hline
\end{tabular}

Fonte: Elaboração própria a partir dos microdados do IBGE Censos Demográficos de 2000 e 2010. 
076 - Qualidade do Emprego nas Culturas de Café, Cana-de-açúcar e Milho: estudo comparativo 2000/2010 entre mesorregiões de Minas Gerais

e Vale do Mucuri, e apenas 38,5\% nas mesorregiões Vale do Rio Doce e Zona da Mata. Para os não qualificados com domicílio rural, os dados foram um pouco melhores, sendo encontrado IQE de $59,1 \%$ nas mesorregiões TMAP e Noroeste de Minas, contra 49,7\% nas mesorregiões Jequitinhonha e Vale do Mucuri e 36\% nas mesorregiões Vale do Rio Doce e Zona da Mata.

A partir da observação geral dos dados, comparando-se as mesorregiões mais modernizadas e menos modernizadas no estado de Minas Gerais, nas três culturas escolhidas, é importante ressaltar que, nitidamente, a maior qualidade do emprego é verificada nas mesorregiões mais modernizadas e as piores, nas menos modernizadas. As mesorregiões mais modernizadas (TMAP e Noroeste de Minas) mostram uma particularidade importante, pois a categoria que apresenta a maior qualidade do emprego é a de empregados qualificados com domicílio rural, sendo visível que o aumento do número de empregados qualificados no setor rural nesta mesorregião alcançou melhores condições de emprego que as demais mesorregiões analisadas.

A maior qualificação dos empregados se dá em decorrência da modernização, conforme Balsadi (2002):

[...] a utilização de máquinas e implementos agrícolas cada vez mais sofisticados (decorrentes da maior modernização) aumenta o grau de exigência dos produtores em relação à qualificação dos operadores agrícolas (BALSADI, 2002, p. 101).

Por outro lado, nas mesorregiões menos modernizadas, os indicadores de qualidade do emprego (IQE) estão bem abaixo quando comparados com os das mesorregiões mais modernizadas, situação que ocorre principalmente quando se tratam de qualificados rurais. É interessante observar também que o IQE, para as mesorregiões de PIB per capita intermediário (Vale do Rio Doce e Zona da Mata), é mais baixo que para as mesorregiões com PIB per capita baixo (Jequitinhonha e Vale do Mucuri).

Nesse sentido, reforça-se a indicação de que a qualidade do emprego é inferior para as mesorregiões menos modernizadas, principalmente no que tange ao emprego qualificado.

Uma questão pertinente que se coloca é que a qualidade do emprego nas mesorregiões mais moder- nizadas foi melhor, em 2010, para os empregados qualificados com domicílio rural, sendo estes empregados com domicílio rural, nas mesorregiões TMAP e Noroeste de Minas, a única categoria que obteve melhoria na década, com progresso relativo ${ }^{6}$ de $6 \%$, enquanto os empregados qualificados e não qualificados com domicílio urbano tiveram uma piora, com progresso relativo negativo de $-20 \%$ e $-2 \%$, respectivamente. Para os empregados qualificados rurais que obtiveram a melhor condição de trabalho $(66,5 \%$ em 2010), o progresso relativo foi negativo na década, de $-5 \%$.

Pode-se concluir que as mesorregiões mais modernizadas tendem a ter maior qualidade do emprego que as menos modernizadas principalmente para os empregados qualificados com domicílio rural; e esses empregados também têm obtido melhores rendimentos e maior grau de formalização quando comparados aos empregados das regiões menos modernizadas, que ainda apresentam alta precariedade do emprego, como a queda no rendimento e o indicador de formalização.

Nesse sentido, uma questão importante deve ser considerada, a de que a qualidade do emprego nas mesorregiões mais modernizadas está atrelada a, basicamente, dois fatores: os indicadores positivos de formalidade, verificando-se aumento de empregados com carteira assinada e de contribuição à Previdência, e o indicador rendimento, que aumentou na década, principalmente para o empregado qualificado (esses dois indicadores registraram queda nas mesorregiões menos modernizadas). A associação positiva entre modernização e renda ainda está de acordo com a leitura de Kageyama e Hoffman (1985). Conforme os autores:

Há uma relação direta entre modernização e concentração de renda no Brasil, considerando que os resultados da revolução verde geraram um aumento das desigualdades, principalmente entre os produtores comerciais e os pequenos produtores de subsistência. E que a agricultura brasileira traz em seu processo de modernização elementos de aumento das desigualdades de renda neste setor, em que as regiões de agricultura mais desenvolvida tendem a concentrar os mais

6. Velocidade relativa da melhoria nas condições e qualidade do trabalho, de acordo com Kageyama e Rehder (1993). 
altos graus de desigualdade na distribuição de renda (KAGEYAMA; HOFFMAN, 1985, p. 174).

E, também,

As mesorregiões mais modernizadas de agricultura mais desenvolvida foram as que apresentaram maior qualidade do emprego e rendimentos bem superiores às menos modernizadas. No outro extremo, se situam as mesorregiões mais pobres e menos modernizadas: Jequitinhonha e Vale do Mucuri, caracterizadas pela grande presença de pequenos agricultores de subsistência, vinculadas a áreas menores de terra, e foram as que apresentaram os piores indicadores em relação à qualidade do emprego, rendimento e formalização, o que pode estar indicando que a modernização beneficia os grandes produtores, em detrimento dos pequenos [...] e que a expansão da modernização significou um agravamento da concentração fundiária e provavelmente da concentração de renda (KAGEYAMA; HOFFAMAN, 1985, p. 177).

Essa é uma realidade que marca a grande heterogeneidade dos empregados agrícolas das culturas dinâmicas selecionadas, privilegiando as mesorregióes mais modernizadas em detrimento das menos modernizadas. Nesse aspecto, a modernização, dessas culturas continua promovendo uma desigualdade regional no estado, beneficiando as mesorregiões mais dinâmicas e ricas em detrimento das mais pobres e, ainda hoje, provoca redução no volume total de trabalhadores.

\section{Conclusões}

Algumas considerações podem ser levantadas a partir dos resultados obtidos, primeiramente, em relação à quantidade de empregados agrícolas. De modo geral, houve uma tendência, entre 2000 e 2010, de aumento do número de empregados qualificados e de queda dos empregados não qualificados em todas as mesorregiões estudadas. Não obstante o aumento dos empregados qualificados, o maior volume de empregados agrícolas em todas as mesorregiões de Minas Gerais continuou sendo o de não qualificados, que apresentou substantiva queda ao longo do período, em todas as mesorregiões selecionadas, situação que resultou em um saldo geral absoluto negativo de 170.776 empregados, pois, no Censo de 2000, eram 390.779 empregados nas três culturas analisadas e, em 2010, caiu para 220.003 , com maior peso para a atividade cafeeira, responsável por 90,8\% desse volume.

Em relação ao perfil dos empregados qualificados e não qualificados com domicílio urbano ou rural, com exceção das mesorregiões Vale do Rio Doce e Zona da Mata, as demais mesorregiões menos modernizadas apresentaram a maior oferta de empregos para os empregados não qualificados com domicílio rural. Já nas mesorregiões mais modernizadas, o maior volume de empregos foi destinado aos empregados não qualificados com domicílio urbano. Assim, com as exceções colocadas, existe uma tendência de a modernização absorver mais os empregados não qualificados com domicílio urbano (considerando-se a baixa quantidade dos empregados rurais), enquanto os empregados não qualificados com domicílio rural têm se inserido nas culturas das mesorregiões menos modernizadas.

Voltando-se para as condições de emprego, o Índice de Qualidade do Emprego (IQE) para os empregados qualificados (com residência tanto no meio urbano quanto no rural) piorou ao longo da década em todas as mesorregiões. Entretanto, o IQE nas mesorregiões mais modernizadas foi maior para os empregados qualificados com domicílio rural, não ocorrendo o mesmo para as demais mesorregiões. Em relação ao indicador parcial de educação (Ind_Educ), apresentou aumento para todos os assalariados de todas as mesorregiões, não condizente com a melhora dos demais indicadores para esta categoria. Identifica-se, assim, um quadro em que houve perda de qualidade do emprego a partir de quedas nos rendimentos, mas com aumento nos níveis educacionais.

Se isso for somado ao aumento da quantidade de empregos qualificados ao longo da década, pode-se sugerir um quadro que revela haver aumento na quantidade de trabalhadores qualificados com maior nível de escolarização, mas que passaram a ser contratados em condições de formalidade mais precárias (carteira assinada e Previdência) e com piores indicadores de renda (Ind_Renda), nas mesorregiões mais modernizadas, inclusive. Esses resultados são compatíveis com a análise de Maia e Sakamoto (2014), para quem o processo de tecnificação da produção agrícola aumentou 
078 - Qualidade do Emprego nas Culturas de Café, Cana-de-açúcar e Milho: estudo comparativo 2000/2010 entre mesorregiões de Minas Gerais

a demanda por mão de obra assalariada mais qualificada nas áreas rurais, mas essa mão de obra disponível para o trabalho não resultou em melhores níveis de renda. Dessa forma, poder-se-ia sugerir que os trabalhadores assalariados nas três culturas analisadas, de modo geral, findam por aceitar essa situação premida pelo desemprego gerado pelo próprio processo que elevou o número de qualificados e redução em maior proporção do contingente de não qualificados, ou seja, por estarem pressionados pela modernização (mecanização) agrícola.

Logo, mesmo com a melhoria do nível educacional, chama a atenção o grande contingente de empregados apenas alfabetizados e aqueles com até oito anos de instrução (fundamental incompleto). Esse movimento pode estar sugerindo um sutil processo de aumento da escolaridade dos empregados rurais, embora ainda exista um número relativamente grande dos empregados com baixa instrução. Todavia, o aumento do indicador parcial de educação não resultou em aumento do indicador renda, fato comprovado por Balsadi et al. (2006).

Em termos de rendimentos mensais médios, foi possível observar uma discrepância entre as mesorregiões mais e menos modernizadas. Nas mesorregiões mais modernizadas (TMAP e Noroeste de Minas), observou-se um aumento da renda média mensal para todos os empregados, com maior ênfase para os qualificados. $\mathrm{O}$ mesmo não ocorreu nas mesorregiões menos modernizadas. Esses dados apontam para uma questão importante: as mesorregiões mais modernizadas tendem a possuir maior qualidade do emprego, assim como a presença maior de empregados qualificados (apesar de essa qualidade abranger um número pequeno de empregados), em contraste com as mesorregiões menos modernizadas, em que predominam empregados não qualificados. Nesse aspecto, a modernização pode estar acentuando as desigualdades ao privilegiar as regiões mais desenvolvidas e ricas, com presença de médios e grandes produtores em detrimento das menos desenvolvidas, com predomínio de pequenos produtores e pobres. Esses resultados reforçam e tornam atual o argumento defendido por Kageyama (2008), de que a modernização agrícola é o processo dominante, que dá direção e conteúdo às transformações do setor agrícola sob o domínio do capital, mas, ao mesmo tempo, é um processo concentrador e desigual.

\section{Referências}

BALSADI, O. V. Características do Emprego Rural no Estado de São Paulo nos anos 90. Dissertação de (Mestrado) Instituto de Economia, Universidade Estadual de Economia, Campinas, 2000.

. Mudanças rurais e o emprego no estado de São Paulo nos anos 90. São Paulo: Annablume, 2002.

Qualidade do emprego e condições de vida das famílias dos empregados na agricultura brasileira no período 1992-2004. Texto para Discussão, Brasília, v. 25 , p. 1-134, 2007

BASTOS, S.; GOMES, J. Mudança na Composição da Produção Agrícola Mineira: análise das culturas dinâmicas (1994-2008). Encontro Nacional de Economia Política, 16. Anais... Uberlândia, 2011.

FERREIRA JÚNIOR, S.; BAPTISTA, A.J.M.S.; LIMA, J.E. A modernização agropecuária nas microrregiões do Estado de Minas Gerais. Brasília: SOBER. Revista de Economia e Sociologia Rural, v. 42, n. 1, 2004.

FIGUEIREDO, N.M.S. Modernização, distribuição de renda e pobreza na agricultura brasileira: 1875, 1980, 1985. Tese (Doutorado) - ESALQ/USP, São Paulo, 1996.

FUNDAÇÃO JOÃO PINHEIRO. Perfil de Minas Gerais. Belo Horizonte. FJP, 2000.

GRAZIANO DA SILVA, J. Progresso técnico e relações de trabalho na agricultura paulista. Tese (Doutorado) Unicamp, São Paulo, 1980.

A modernização dolorosa: estrutura agrária, fronteira agrícola e trabalhadores rurais no Brasil. Rio de Janeiro: Zahar , 1981.

. O novo rural brasileiro. Campinas-SP: UNICAMP-IE, 1999. (Coleção Pesquisas, Vol. 1).

IBGE - Instituto Brasileiro de Geografia e Estatística. Censo Demográfico 2000. Disponível em: <http://www. ibge.gov.br>. Acesso em: 2015

.Censo Demográfico 2010. Disponível em: <http:// www.ibge.gov.br>. Acesso em: 2015.

KAGEYAMA A. Desenvolvimento rural. Conceitos e aplicação ao caso brasileiro. Porto Alegre: UFRGS, 2008.

.; LEONE, E.T. Trajetórias da modernização e emprego agrícola: Brasil, 1985-1996. Revista de Economia e Sociologia Rural, Brasília, v. 40, n. 1, p. 9-28, 2002.

.; HOFFMAN, R. Modernização da agricultura e distribuição de renda no Brasil. Pesquisa e Planejamento Econômico, Rio de Janeiro, v. 15, n. 1, p. 171-208. 1985. 
.; REHDER, P.O. Bem-estar rural no Brasil na década de oitenta. Revista de Economia e Sociologia Rural, Brasília, v. 31, n. 1, p. 23-44, jan./mar. 1993.

; SILVEIRA, J.M.J. Agricultura e questão regional. Revista de Economia e Sociologia Rural, Brasília-DF, v. 35, n. 2, p. 9-33, 1997.

MAIA, A. G.; SAKAMOTO. A nova configuração do mercado de trabalho agrícola Brasileiro. In BUAINAIN, A.M. et al. O mundo rural no Brasil do século 21: a formação de um novo padrão agrário e agrícola. Brasília-DF: Embrapa, 2014.

ORTEGA, A. C.; JESUS, C. M. A modernização da atividade cafeeira e seus impactos na estrutura produtiva e sobre o pessoal ocupado no Território do Café do Cerrado. In: XLVIII Congresso da Sober, 2010, Campo Grande. Tecnologias, desenvolvimento e integração. Brasília: Sober, Anais..., 2010, v. 1, p. 1-20.

. Café e território: a cafeicultura no cerrado mineiro. Campinas: Alínea, 2012.

RIBEIRO, A.E.M.; AYRES, E.C.B.; ASSIS, T.R. O trabalho rural nas muitas Minas. Economia Ensaios, Uberlândia, v. 16, n. 1, p. 119-140, 2003.

TEIXEIRA F. A. O processo de expansão da cana de açúcar e seus impactos sobre a qualificação do trabalhador: análise comparativa para os estados de Minas Gerais, Goiás, São Paulo, Paraná e Mato Grosso do Sul. Tese (Doutorado) - Universidade Federal de Uberlândia, 2015.

Todo o conteúdo deste periódico, exceto onde estiver identificado, está licenciado sob uma Licença Creative Commons (cc by 4.0). 
